ORIGINAL ARTICLE

\title{
The Role of Chlorhexidine in the Prevention of Pin Tract Infection as Compared to Povidone-lodine in Patients Managed by Ilizarov Circular Fixator
}

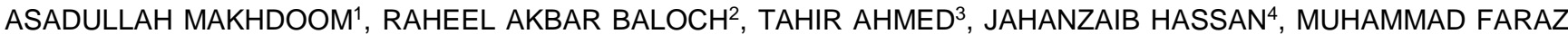 \\ $J \mathrm{KKHIO}^{5}$, LACHMAN DAS MAHESHWARI ${ }^{6}$, MOIZ AHMED ${ }^{7}$ \\ ${ }^{1}$ Professor, Department of Orthopaedic Surgery, Liaquat University of Medical \& Health Sciences (LUMHS), Jamshoro, Pakistan \\ ${ }^{2,3,4}$ Consultant, Department of Orthopaedic Surgery, Liaquat University Hospital, Hyderabad Pakistan \\ ${ }^{5}$ Assistant Professor, Department of Orthopaedic Surgery, Liaquat University of Medical and Health Sciences, Jamshoro, Pakistan \\ ${ }^{6}$ Senior Registrar, Department of Orthopaedic Surgery, Liaquat University of Medical and Health Sciences, Jamshoro, Pakistan \\ ${ }^{7}$ Medical Officer, Department of Medicine, Jinnah Postgraduate Medical Center, KarachiPakistan \\ Corresponding author:Dr. Raheel Akbar Baloch, Email: dr.rabaloch@gmail.com, Cell No.+923342121125
}

\begin{abstract}
Objective: To compare the efficacy of Chlorhexidine in the prevention of pin tract infection as compared to Povidone-iodine antiseptic.

Study Design: Prospective, single blinded randomized trial.

Study Setting and Duration: Liaquat University of Health Science (LUMHS), Jamshoro between July 2018 to November 2020.

Methodology: All patients who underwent llizarov external fixation as per indications were eligible for the study. Individuals with a previous history of osteomyelitis were excluded from the study. Pin sites were cleansed with normal saline using clean applicators. In the group chlorhexidine, the antiseptic was applied on the pin skin interphases (1\% chlorhexidine). Similarly, $10 \%$ povidone iodine was applied to patients in group C. The control group was cleansed with normal saline. Pin sites were either dressed daily or weekly. The primary outcome was the rate of pin site infection days.

Results: Chlorhexidine group had significantly lesser pin-site infections as compared to the povidone-iodine group with a frequency of $13(39.39 \%)$ and $19(63.33 \%), p=0.04$, respectively. The mean pin tract infection rate days \pm SD were significantly lower in the chlorhexidine group as compared to the povidone-iodine group (1.35 \pm 2.26 vs $3.54 \pm 4.30, p=0.041)$. Similarly, the mean duration to onset of pin site infection was also significantly higher in the chlorhexidine group compared to povidone-iodine and control groups.
\end{abstract}

Conclusion: Patients who used Chlorhexidine as the cleansing agent had significantly fewer pin-site infections as compared to the povidone-iodine group.

Keywords: Chlorhexidine, llizarov fixator, fracture, Povidone-iodine

\section{INTRODUCTION}

The llizarov fixator is widely used for fracture fixation and stabilization, deformity correction, limb lengthening and reconstructive surgery. ${ }^{1}$ The llizarov wires are inserted from one side of the skin of the limb, passed through the bone and exit from the opposite side, hence establishing a permanent open channel which is an easy route for possible infectious agents to enter the body. ${ }^{2-3}$

Pin site infection (generally caused by staphylococcus aureus) is the most common complication using external fixators. The incidence of pin tract infections vary between $3 \%$ and $80 \%$. ${ }^{4}$ According to a study by Parameswaran et al., the rate of pin tract infection in the study was $11.2 \% .{ }^{5}$

Along with other less frequent complications such as loss of fixation, nonunion, delayed union and malunion, pin tract infection increases morbidity among patients. Untreated infections may further lead to osteomyelitis. ${ }^{6}$

Literature shows that a minimal pin-care protocol as directed by the surgeon can minimize the risk of postoperative pin-site infections. However, there is still no consensus about the most optimum pin-site care protocol. ${ }^{7}$ ${ }^{8}$ The factors that may impact the risk of pin-site infections may include, frequency of pin site care dressing, type of wires used, duration of antibiotics, and the cleansing agent or antiseptic. ${ }^{9-10}$
The present study aimed to compare the role of chlorhexidine in the prevention of pin tract infection as compared to Povidone-iodine.

\section{METHODS AND MATERIALS}

A prospective, randomised, single blinded study was performed at LUMHS between July 2018 and November 2020 for a period of 24 months. Ethical approval was obtained from the Institutional Review Board (IRB). Informed consent was also secured from all the patients who were recruited for the study.

All surgical procedures were performed by a single orthopaedics consultant using the standard wire and half pin insertion techniques. Irrespective of the patient's age and gender, all those who were offered llizarov external fixation as per indications were eligible for the study. Patients were asked for their consent of participation with regular follow-ups for pin-site monitoring. Individuals with a previous history of osteomyelitis, active infection, and those who refused to partake in the study were excluded from the study.

It was a three arm trial, with one group acting as the control group while the other two groups used either chlorhexidine and Povidone-iodine as antiseptics to care for the pin site wound. 
Sample size was calculated using online software www.selectstatistics.com. Reference article was based on a study by Lee et al. ${ }^{11}$ The power was kept as 95\% with significance level of $5 \%$, a minimum of 561 pin sites must be observed in each group to determine statistical significance.

A total of 95 number of patients were enrolled in the study and were grouped randomly into one of the three groups, i) Chlorhexidine group, ii) Povidone-iodine group, and iii) Control group. In our study, a person was assigned to evaluate the final outcome who was blinded to the intervention and followed-up the patients weekly. There were 32 patients in the control group, 30 patients in the povidone iodine group, and 33 patients in the chlorhexidine group.

Pin sites were cleansed with normal saline using clean applicators. In the group chlorhexidine, the antiseptic was applied on the pin skin interphases (1\% chlorhexidine). Similarly, $10 \%$ povidone iodine was applied to patients in group C. Dry gauze pieces were placed on pin sites. Pin sites were either dressed daily or weekly. The pin sites were color labeled according to the frequency of dressing.

Follow-up assessment was performed by a dedicated blinded observer. He assessed all pin sites once weekly for any evidence of infection. The person who observed the outcome assessed the patients weekly at follow-ups and documented any pin site infections. We collected sociodemographic data (age, gender, comorbids, etc), surgical indication, application and removal of llizarov fixator, follow-up duration, type of pin (transverse wire or half pin), total number of wires and half pins found infected were recorded and graded according to Paley's classification and treated accordingly to latest guidelines.
Patients were followed up until the fracture was united and pins and wires were removed.

The primary outcome was the rate of pin site infection days. The numerator was calculated by multiplying the number of infected pin sites by the duration (in days) of infection. The denominator was calculated by multiplying the total number of pin sites by the total number of days of observation. To obtain the mean rate of pin site infection days, the sum of numerators was divided by the sum of denominators. This was done for all three groups and compared to determine any statistical difference between the groups.

SPSS version 26 was used to summarize all variables using a number of observations for analysis of the results. Pearson's chi square test and independent t-test were used to compare the categorical variables between the study groups. $p$ value $<0.05$ was considered statistically significant.

\section{RESULTS}

A total of 95 patients were included in the study. The mean age in the control group, chlorhexidine, and povidoneiodine groups were $37.96 \pm 14.09,36.33 \pm 15.31$, and $35.03 \pm 14.60$ years, respectively. Male gender was dominant in all three groups. The mean weight of patients in the chlorhexidine group versus the povidone-iodine group was $63.40 \pm 14.11$ versus $62.95 \pm 13.95 \mathrm{kgs}$. The ilizarov sites are mentioned in table 1. Sixteen patients, $50 \%$ in the control group, nineteen patients in group chlorhexidine, and $15(50 \%)$ in the povidone-iodine group had ilizarov fixator on the leg (See table 1).

Table 1. The sociodemographic and clinical characteristics of study participants

\begin{tabular}{|l|l|l|l|}
\hline \multicolumn{2}{|l|}{ Control $(\mathrm{n}=32)$} & Chlorhexidine $(\mathrm{n}=33)$ & Povidone iodine $(\mathrm{n}=30)$ \\
\hline Age (years) & $37.96 \pm 14.09$ & $36.33 \pm 15.31$ & $35.03 \pm 14.60$ \\
\hline Gender & $26(81.25 \%)$ & $28(84.85 \%)$ & $26(86.67 \%)$ \\
\hline Male & $6(18.75 \%)$ & $5(15.15 \%)$ & $4(13.33 \%)$ \\
\hline Female & $61.37 \pm 13.42$ & $63.40 \pm 14.11$ & $62.95 \pm 13.95$ \\
\hline Mean weight (kg) & $3(9.38 \%)$ & $2(6.06 \%)$ & $2(6.67 \%)$ \\
\hline Comorbid & $2(6.25 \%)$ & $2(6.06 \%)$ & $1(3.33 \%)$ \\
\hline Diabetes & \multicolumn{3}{l|}{} \\
\hline Hypertension & $4(12.50 \%)$ & $7(21.21 \%)$ & $5(16.67 \%)$ \\
\hline Segment where llizarov was applied & $2(6.25 \%)$ & $1(3.03 \%)$ & $1(3.33 \%)$ \\
\hline Upper Limb & $16(50.00 \%)$ & $19(57.58 \%)$ & $15(50.00 \%)$ \\
\hline Thigh & $6(18.75 \%)$ & $4(12.12 \%)$ & $6(20.00 \%)$ \\
\hline Leg & $4(12.50 \%)$ & $2(6.06 \%)$ & $3(10.00 \%)$ \\
\hline Ankle and foot & & \\
\hline Thigh and leg both & & \\
\hline
\end{tabular}

Table 2.Comparison of primary outcomes across three treatment groups.

\begin{tabular}{|l|l|l|l|l|}
\hline & Control $(n=32)$ & $\begin{array}{l}\text { Chlorhexidine } \\
(n=33)\end{array}$ & $\begin{array}{l}\text { Povidone iodine } \\
(\mathrm{n}=30)\end{array}$ & $p$-value \\
\hline Patients who had pin site infections & $22(68.75 \%)$ & $13(39.39 \%)$ & $19(63.33 \%)$ & $0.040^{\alpha}$ \\
\hline Pin tract infection rate days, per 1000 pin tract days observed \pm SD & $3.31 \pm 4.42$ & $1.35 \pm 2.26$ & $3.54 \pm 4.30$ & $0.041^{\beta}$ \\
\hline Mean duration to onset of pin site infection, days \pm SD & $26.41 \pm 34.89$ & $52.22 \pm 55.32$ & $30.86 \pm 37.78$ & $0.045^{\beta}$ \\
\hline
\end{tabular}

$\alpha=$ Chi-Square test

$\beta=$ Kruskal Wallis test 
Table 2 represents the primary outcomes across the three treatment groups in our study. The study reveals that individuals in chlorhexidine groups had significantly lesser number of pin-site infections as compared to the povidoneiodine group and the control group with a frequency of 13 (39.39\%), 19 (63.33\%), and 22 (68.75\%), $p=0.04$, respectively. The mean pin tract infection rate days, per 1000 pin tract days observed \pm SD were significantly lower in the chlorhexidine group as compared to the povidoneiodine group $(1.35 \pm 2.26$ vs $3.54 \pm 4.30, p=0.041)$. Similarly, the mean duration to onset of pin site infection was also significantly higher in chlorhexidine group compared to povidone-iodine and control groups i.e. 52.22 \pm 55.32 vs $30.86 \pm 37.78$ vs $26.41 \pm 34.89$ ( $p=0.045)$. See table 2 for details.

\section{DISCUSSION}

One of the most common complications associated with the Ilizarov fixation is the pin site infections. Despite the growing techniques and improvements in pin site care standards, infection of the pin site remains a challenging issue. Health practitioners hold diverse views regarding the best cleansing agent and there is a dire need for evidence based clinical practice to determine the most effective agent for minimizing the rates of infection. ${ }^{12-13}$

In the present study, we evaluated the efficacy of chlorhexidine - a prominent antiseptic, in preventing the pin site infection as compared to the standard antiseptic povidone-iodine. Our study reported that patients who used Chlorhexidine as the cleansing agent had significantly fewer pin-site infections as compared to the povidoneiodine group as well as the control group $(p=0.04)$. Furthermore, the mean pin tract infection rate days were also significantly lower in the chlorhexidine group as compared to the povidone-iodine group $(p=0.041)$.

In a study by Kenneth E et al., 23 (19\%) patients had a pin track related complications. Furthermore, the authors claimed that increasing age was significantly associated with augmented risk of pin track complications $(p<0.05){ }^{14}$ Gordon et al., revealed that a nihilistic approach for pin-site care after external fixation provides good patient outcome with only $4 \%$ patients developing pin tract infections. The authors ensured that the participants only used daily showering without any physical cleansing. However, the study did not use any other comparative groups therefore, the significance of their findings are limited. ${ }^{15}$ Furthermore, the study was only conducted on children. In our study, we found chlorhexidine to be a more superior antiseptic in preventing the risk of pin-site infections postoperatively.

The complications such as pin-site infections associated with external fixation can result in substantial morbidity, more prominently in high-risk patients, subsequently leading to soft tissue healing issues or osteomyelitis in some cases. ${ }^{16}$ Therefore, taking adequate care of pin-site is absolutely necessary with the most optimum antiseptic available.

Schweinberger and Roukis conducted a retrospective study to explore the role of a weekly, surgeon-guided pin site care routine in preventing pin site infections among a group of high-risk individuals. They found that weekly pinsite care protocol abated the rate of pin site infections. ${ }^{17}$
Dahl and Larsen compared the two cleansing agents i.e. sodium chloride and chlorhexidine solution. The authors revealed that chlorhexidine was more efficacious than sodium chloride as a cleansing agent for pin site care protocol. 18 The results noted in the current study were comparable to the results published previously. 19-20

\section{CONCLUSION}

The present study concludes that chlorhexidine solution served as a significantly better cleansing agent than Povidone-iodine solution in patients who underwent llizarov external fixation. Patients who used Chlorhexidine as the cleansing agent had significantly fewer pin-site infections as compared to the povidone-iodine group.

\section{REFERENCES}

1. Spiegelberg B, Parratt T, Dheerendra SK, Khan WS, Jennings R, Marsh DR. llizarov principles of deformity correction. The annals of the royal college of surgeons of England. 2010 Mar;92(2):101-5.

2. Gubin AV, Borzunov DY, Malkova TA. The llizarov paradigm: thirty years with the llizarov method, current concerns and future research. International orthopaedics. 2013 Aug;37(8):1533-9.

3. Liu Y, Yushan M, Liu Z, Liu J, Ma C, Yusufu A. Complications of bone transport technique using the llizarov method in the lower extremity: a retrospective analysis of 282 consecutive cases over 10 years. BMC Musculoskeletal Disorders. 2020 Dec;21:1-9.

4. Jennison $\mathrm{T}, \mathrm{McNally} \mathrm{M}$, Pandit $\mathrm{H}$. Prevention of infection in external fixator pin sites. Actabiomaterialia. 2014 Feb 1;10(2):595-603.

5. Parameswaran AD, Roberts CS, Seligson D, Voor M. Pin tract infection with contemporary external fixation: how much of a problem?. Journal of orthopaedic trauma. 2003 Aug 1;17(7):503-7.

6. Ceroni D, Grumetz C, Desvachez O, Pusateri S, Dunand P, Samara E. From prevention of pin-tract infection to treatment of osteomyelitis during paediatric external fixation. Journal of children's orthopaedics. 2016 Dec 1;10(6):605-12.

7. W-Dahl A, Toksvig-Larsen S, Lindstrand A. No difference between daily and weekly pin site care A randomized study of 50 patients with external fixation. ActaOrthopaedicaScandinavica. 2003 Jan 1;74(6):704-8.

8. Checketts RG, MacEachem AG, Otterbum M. Pin track infection and the principles of pin site care. InOrthofix external fixation in trauma and orthopaedics 2000 (pp. 97103). Springer, London.

9. Davies R, Holt N, Nayagam $\mathrm{S}$. The care of pin sites with external fixation. The Journal of bone and joint surgery. British volume. 2005 May;87(5):716-9.

10. Atiyeh BS, Dibo SA, Hayek SN. Wound cleansing, topical antiseptics and wound healing. International wound journal. 2009 Dec;6(6):420-30.

11. Lee CK, Chua YP, Saw A. Antimicrobial gauze as a dressing reduces pin siteinfection: a randomized controlled trial. ClinOrthopRelat Res 2012;470(2):610-5.

12. Hamahashi K, Uchiyama $Y$, Kobayashi $Y$, Watanabe M. Delayed methicillin-resistant Staphylococcus aureus-induced osteomyelitis of the tibia after pin tract infection: two case reports. Journal of medical case reports. 2017 Dec;11(1):16.

13. Subramanyam KN, Mundargi AV, Potarlanka R, Khanchandani $P$. No role for antiseptics in routine pin site care in llizarov fixators: a randomised prospective single blinded control study. Injury. 2019 Mar 1;50(3):770-6. 
14. Egol, Kenneth A. MD1; Paksima, Nader DO, MPH1; Puopolo, Steven MD1; Klugman, Jeffrey MD1; Hiebert, Rudi MSc1; Koval, Kenneth J. MD2 Treatment of External Fixation Pins About the Wrist: A Prospective, Randomized Trial, The Journal of Bone \& Joint Surgery: February 2006 Volume 88 - Issue 2 - p 349-354 doi: 10.2106/JBJS.E.00011

15. Gordon, J. Eric M.D.; Kelly-Hahn, Jill R.N.; Carpenter, Chris J. R.N.; Schoenecker, Perry L. M.D. Pin Site Care During External Fixation in Children: Results of a Nihilistic Approach, Journal of Pediatric Orthopaedics: March 2000 Volume 20 - Issue 2 - p 163-165

16. Bibbo C, Brueggeman J. Prevention and management of complications arising from external fixation pin sites. The Journal of foot and ankle surgery. 2010 Jan 1;49(1):87-92.

17. Schweinberger MH, Roukis TS. The Effectiveness of Physician-Directed External Fixation Pin Site Care in Preventing Pin Site Infection in a High-Risk Patient
Population. Foot \& Ankle Specialist. 2008;1(4):218-221. doi:10.1177/1938640008318176.

18. W-Dahl, A., Toksvig-Larsen, S. Pin site care in external fixation sodium chloride or chlorhexidine solution as a cleansing agent. Arch Orthop Trauma Surg 124, 555-558 (2004). https://doi.org/10.1007/s00402-004-0733-y

19. Shabir M, Afridi HU, Inam M, Ali MA, Shah F. Comparison of $1 \%$ Silver Sulphadiazine and Chlorhexidine Dressing Combined Versus 5\% Chlorhexidine Dressing Alone in Preventing Pin Tract Infection in External Fixators. Journal of Pakistan Orthopaedic Association. 2019 Nov 30;31(03):1226.

20. Suarsedewi DW. PIN SITE CARE USING CHLORHEXIDINE; CASE STUDY REPORT. JUMANTIK (JurnalllmiahPenelitianKesehatan). 2017 Aug 27;2(1):90-9. 